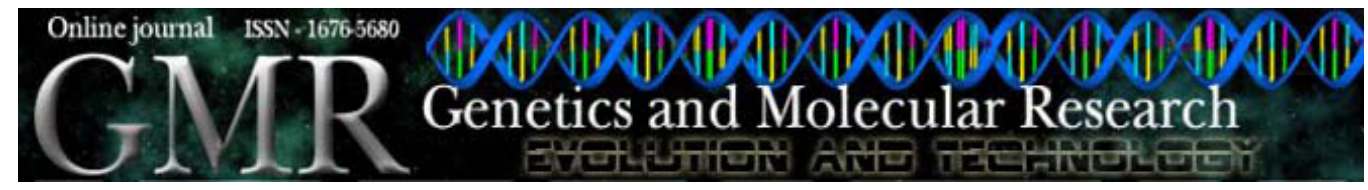

\title{
The G1138A mutation rate in the fibroblast growth factor receptor 3 (FGFR3) gene is increased in cells carrying the $t(4 ; 14)$ translocation
}

\author{
P.L. Reddy and R.P. Grewal \\ Laboratory of Neurogenetics, New Jersey Neuroscience Institute, \\ JFK Medical Center, Edison, NJ, USA \\ Corresponding author: R.P. Grewal \\ E-mail: rgrewal@solarishs.org
}

Genet. Mol. Res. 8 (2): 435-439 (2009)

Received December 5, 2008

Accepted March 9, 2009

Published April 22, 2009

\begin{abstract}
Spontaneous mutations are a common phenomenon, occurring in both germ-line and somatic genomes. They may have deleterious consequences including the development of genetic disorders or, when occurring in somatic tissues, may participate in the process of carcinogenesis. Similar to many mutational hotspots, the G1138A mutation in the fibroblast growth factor receptor 3 (FGFR3) gene occurs at a CpG site. In germ-line tissues, the G1138A mutation results in achondroplasia and has one of the highest spontaneous mutation rates in the human genome. Although not at the G1138A site, there are increased rates of other somatic mutations in the FGFR 3 gene that have been reported in multiple myeloma cases associated with a translocation, $\mathrm{t}(4 ; 14)$. The chromosome- 4 break points in this translocation are clustered in a $70-\mathrm{kb}$ region centromeric to the FGFR3 gene. We hypothesized that this translocation may impact the mutation rate at the G1138A site. We employed a semi-quantitative polymerase chain reaction-based assay to measure the frequency of this mutation in multiple myeloma cell lines carrying t $(4 ; 14)$ translocation. Analysis of these cell lines varied from no change to a 10 -fold increase in the mutation frequency compared with normal controls. In general, there was an increase in the G1138A mutational frequency suggesting that chro-
\end{abstract}


mosomal rearrangement can affect the stability of the $\mathrm{CpG}$ hotspots.

Key words: Spontaneous mutation; Translocation; G1138A mutation; Homo sapiens; Multiple myeloma; Semi-quantitative assay

\section{INTRODUCTION}

The human genome is dynamic, and spontaneous mutations occur in both germ-line and somatic tissues. Depending upon the gene involved, germ-line mutations may result in the development of sporadic genetic disorders. These can include both autosomal dominant and X-linked diseases, such as Apert's syndrome, neurofibromatosis type I or hemophilia. Many of these diseases are caused by point mutations that occur at $\mathrm{CpG}$ sites. Although $\mathrm{CpG}$ dinucleotides are under represented in the human genome by a factor of up to five, they are found at the sites of up to $37 \%$ of all germ-line mutations causing sporadic genetic diseases (Cooper and Youssoufian, 1988; Schorderet and Gartler, 1992). It is hypothesized that this high frequency is due to spontaneous methylation, followed by deamination of the $\mathrm{CpG}$ cytosine, resulting in a C-to-T transition. If such point mutations occur in particular genes in somatic tissues, they may contribute to the development of malignancy (Jones, 1996). There are significant regional genomic differences in the frequency of mutation between various $\mathrm{CpG}$ sites. The mechanisms by which some of these sites result in mutational hotspots are unknown.

Fibroblast growth factor receptor 3 (FGFR3) is a transmembrane glycoprotein and belongs to a family of tyrosine kinase receptor genes (FGFR $1-4)$. These genes are involved in regulating cell growth, wound healing and malignant transformation (Coumoul and Deng, 2003). Germ-line mutations involving $F G F R 3$ can cause genetic skeletal dysplasias such as achondroplasia $(\mathrm{ACH})$, thanatophoric dysplasia, hypochondroplasia, and Muenke craniosynostosis. A number of somatic mutations in this gene have been described in malignancies including multiple myeloma (MM). Many of the somatic mutations identified in these cancers are similar to those observed in the genetic skeletal dysplasias (Richelda et al., 1997; Chesi et al., 1997; Cappellen al., 1999; van Rhijn et al., 2002).

$\mathrm{ACH}$ is an autosomal dominant disorder and is the most frequent cause of short limbed dwarfism. Moreover, $95 \%$ of ACH cases are due to a single, recurrent point mutation in the FGFR3 gene. This is the G1138A mutation that results in a glycine to arginine substitution at codon 380 . More than $80 \%$ of all $\mathrm{ACH}$ cases are sporadic and caused by this recurrent mutation. It has been estimated that the mutation rate at this site is $10^{-5}$ per generation, the highest rate reported in the human genome (Rousseau et al., 1994; Bellus et al., 1995).

In the United States, MM is the most common form of plasma cell dyscrasia. The annual incidence is 3-4/100,000 per year, with an estimated 14,000 new cases each year. Multiple myeloma is characterized by a marked heterogeneity of genetic lesions, one of which is the $t(4 ; 14)$ translocation, which occurs in about $15 \%$ of patients. This translocation is associated with poor response to first-line chemotherapy (Chesi et al., 1997; Keats et al., 2003). The chromosome-4 break points are clustered in a 70-kb region centromeric to the FGFR3 gene. Genetic analysis of the MM cell lines carrying this translocation has revealed activating mutations in and overexpression of the FGFR3 gene (Chesi et al., 1997; Zhu et al., 2005). The activating mutations, detected by real-time polymerase chain reaction (RT-PCR) and single-strand conformation polymorphism analysis, include A1157G, A1987G and A761G, but not G1138A (Chesi et al., 1997; Onwuazor et al., 2003). 
However, the methods used to identify these mutations are not highly sensitive; they typically only detect at levels above 75,000 copies. Consequently, even 10-fold increases in G1138A mutation levels from 500 to 5000 mutant molecule levels may not be detected by these methods.

We hypothesized that the $t(4 ; 14)$ translocation may increase the frequency of the G1138A mutation. We tested this hypothesis in MM cell lines carrying the translocation by measuring G1138A mutation levels using a previously developed semi-quantitative assay (Grewal, 2005).

\section{MATERIALAND METHODS}

In any PCR, the target DNA is amplified initially at a constant exponential rate, which results in a linear relationship between the logarithm of the amount of initial template and the final amount of the specific amplified product. This principle can be used to estimate the number of initial target molecules (Grewal, 2005).

We employed a negative control, which consisted of genomic DNA (pooled human genomic DNA, \#636401 CLONTECH) with no added mutant ACH. The positive control was genomic DNA admixed with known copy numbers of molecules carrying the G1138A mutation (derived from homozygous achondroplasia, NA08859, Coriell Cell Repositories, Camden, NJ, USA). The MM cell line DNA used in these experiments, KMS 18, H929, JIM3, KHM11, and LP1, was generously provided by Dr. P. Leif Bergsagel, Arizona, USA.

All experiments were done in triplicate; in each replicate, the standards consisted of a negative control (genomic DNA with no admixed mutant $\mathrm{ACH}$ ) and three positive controls, each with different known amounts $(750,1500,3000$ copies) of G1138A genomes admixed with 300,000 copies of wild-type $\mathrm{ACH}$ (equivalent to $1 \mu \mathrm{g}$ genomic DNA). The test samples consisted of $1 \mu \mathrm{g}$ DNA extracted from each of the MM cell lines. In the first round PCR, a 235-bp fragment flanking the 1138 site was amplified from $1 \mu \mathrm{g}$ of both the standard and unknown test samples with $16 \mathrm{PCR}$ cycles $\left(94^{\circ} \mathrm{C}\right.$ for $45 \mathrm{~s}, 50^{\circ} \mathrm{C}$ for $45 \mathrm{~s}, 72^{\circ} \mathrm{C}$ for $\left.30 \mathrm{~s}\right)$, preceded by a 2 -min $95^{\circ} \mathrm{C}$ activation step. Each $50-\mu \mathrm{L}$ reaction contained $1 \mathrm{X}$ Taq buffer $(50 \mathrm{mM} \mathrm{KCl}, 10 \mathrm{mM}$ Tris-HCl,1.5 $\mathrm{mM} \mathrm{MgCl}$ and $0.1 \%$ Triton X-100), 2.5 units Taq DNA polymerase (Promega), $0.4 \mathrm{mM} \mathrm{dNTP}$ (Applied Biosystems) and $0.5 \mu \mathrm{M}$ of each primer (F:5'-AGGAGCTGGTGGAGGCTGA-3' and R:5'-GTGTGTTGGAGCTCATGGAC-3'). In the second step, $2 \mu$ L of the product from the first round was subjected to allele-specific PCR (AS PCR), as previously described (Grewal, 2005). The reaction conditions for this step were as follows: 2 units Taq DNA polymerase and $1 \mathrm{X}$ Taq buffer ( $50 \mathrm{mM} \mathrm{KCl}, 10 \mathrm{mM}$ Tris- $\mathrm{HCl}, 1.5 \mathrm{mM} \mathrm{MgCl}_{2}$ and $0.1 \%$ Triton X-100), and $0.05 \mu \mathrm{M}$ of each primer (F:5'-ATGCAGGCATCCTCAGCTCCA-3' and R:5' -GGGAGATCTTGTGCA CGGTG-3') in a total reaction volume of $50 \mu \mathrm{L}$. The cycling parameters were: $95^{\circ} \mathrm{C}$ for $2.5 \mathrm{~min}$, $30 \mathrm{PCR}$ cycles $\left(95^{\circ} \mathrm{C}\right.$ for $45 \mathrm{~s}, 55^{\circ} \mathrm{C}$ for $25 \mathrm{~s}, 72^{\circ} \mathrm{C}$ for $\left.60 \mathrm{~s}\right)$ and a final extension at $72^{\circ} \mathrm{C}$ for 14 min. Fifteen microliters of the reaction product was then resolved by gel electrophoresis $(6 \%$ polyacrylamide gel at $90 \mathrm{~V}$ for $30 \mathrm{~min}$; BIORAD). The gel was then stained (SYBR gold) and imaged. The AS PCR product band intensity was measured for the mutant allele and the concentration of mutant molecules was then determined as previously described (Soong and Arnheim, 1996; Grewal, 2005).

\section{RESULTS}

Figure 1 shows the plot of integrated density versus the number of mutant molecules 
generated using standard samples with known mutant copy numbers. Using the linear portion of this plot, mutant copy numbers were estimated in the test samples (MM cell lines). All values are the average of three replicates. We found that all the MM cell lines had relatively low copy numbers of G1138A mutant molecules, with an average mutant copy number of 203 counts; the lowest count of $24 \pm 13$ mutant copies was observed in cell line LP1 and the highest mutant copy number was $303 \pm 43$ counts in KMS 18 .

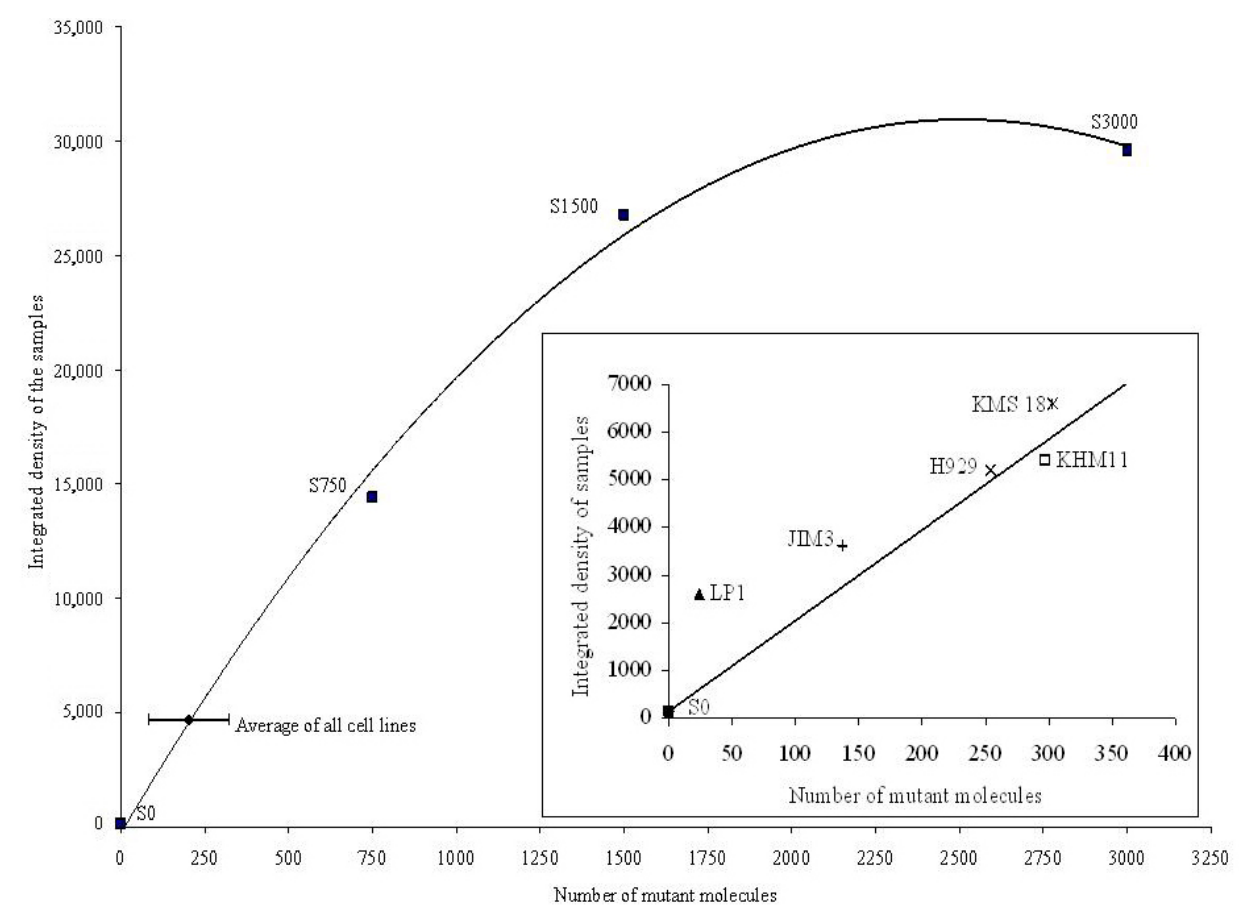

Figure 1. The integrated density corresponding to the number of mutant molecules of standards ( $\mathbf{\square})(0,750,1500$, 3000). The inset shows the points corresponding to the test samples (multiple myeloma cell lines) KMS $18\left({ }^{*}\right.$ ), H929 (x), JIM3 (+), KHM11 ( $\square)$, and LP1 ( $\mathbf{\Delta})$.

\section{DISCUSSION}

In a previous study, we found that the average G1138A levels in two control cell lines were $31 \pm 10$ (HT-29) and $49 \pm 15$ (SW83728) (Grewal, 2005). Compared to these values, semi-quantitative analysis of four of the MM cell lines (JIM3, H929, KHM11, and KMS 18) carrying the translocation showed a 4- to 10-fold increase in the frequency of G1138A. This reinforces the hypothesis that chromosomal rearrangements can affect the stability and/or the function of genes near the site of translocations, leading to accumulation of somatic mutations (Richelda et al., 1997; Chesi et al., 1997; Cappellen al., 1999; van Rhijn et al., 2002).

Translocations in these MM cell lines may result in an increased G1138A mutation rate by influencing the secondary, tertiary and/or the quaternary structure of the local DNA near this site. These changes may alter not only the degree of methylation but also could influence DNA repair. 
How our findings of the increase in mutation frequency at the G1138A site relate to the high paternal germ-line mutation frequency is not clear. It is possible that if the $t(4 ; 14)$ translocation occurred early in the process of spermatogenesis, it would cause an increase in the mutation rate at this site. This could result in a "jackpot" effect, whereby the progeny of a precursor spermatogonial cell carrying the translocation/spontaneous G1138A mutation would all carry this same mutation, resulting in a germ-line mosaic. However, to our knowledge, there is no published information on the frequency of this translocation in spermatogonial cells.

Our study indicates that the stability of the $\mathrm{CpG}$ site associated with the highest spontaneous germ-line mutation rate is affected by chromosomal rearrangements in the somatic cells. Further research is needed to confirm and extend our findings to germ-line tissues. Investigations into the high mutation rate at the G1138A site could provide insight into fundamental mechanisms of mutation, which in turn could have implications for various fields, ranging from clinical genetics to molecular evolution.

\section{ACKNOWLEDGMENTS}

We are grateful to Dr. Leif Bergsagel, Hematology/Oncology, Department of Medicine, Mayo Clinic Arizona, USA, for providing the MM cell line.

\section{REFERENCES}

Bellus GA, Hefferon TW, Ortiz de Luna RI, Hecht JT, et al. (1995). Achondroplasia is defined by recurrent G380R mutations of FGFR3. Am. J. Hum. Genet. 56: 368-373.

Cappellen D, De Oliveira C, Ricol D, de Medina S, et al. (1999). Frequent activating mutations of FGFR3 in human bladder and cervix carcinomas. Nat. Genet. 23: 18-20.

Chesi M, Nardini E, Brents LA, Schrock E, et al. (1997). Frequent translocation t(4;14)(p16.3;q32.3) in multiple myeloma is associated with increased expression and activating mutations of fibroblast growth factor receptor 3. Nat. Genet. 16: 260-264.

Cooper DN and Youssoufian H (1988). The CpG dinucleotide and human genetic disease. Hum. Genet. 78: 151-155.

Coumoul X and Deng CX (2003). Roles of FGF receptors in mammalian development and congenital diseases. Birth Defects Res. C. Embryo Today 69: 286-304.

Grewal RP (2005). A simple and rapid quantitative method of detection of the common achondroplasia mutation: analysis in mismatch repair deficient cells. Genetika 41: 1137-1141.

Jones PA (1996). DNA methylation errors and cancer. Cancer Res. 56: 2463-2467.

Keats JJ, Reiman T, Maxwell CA, Taylor BJ, et al. (2003). In multiple myeloma, t(4;14)(p16;q32) is an adverse prognostic factor irrespective of FGFR3 expression. Blood 101: 1520-1529.

Onwuazor ON, Wen XY, Wang DY, Zhuang L, et al. (2003). Mutation, SNP, and isoform analysis of fibroblast growth factor receptor 3 (FGFR3) in 150 newly diagnosed multiple myeloma patients. Blood 102: 772-773.

Richelda R, Ronchetti D, Baldini L, Cro L, et al. (1997). A novel chromosomal translocation $\mathrm{t}(4 ; 14)(\mathrm{p} 16.3$; q32) in multiple myeloma involves the fibroblast growth-factor receptor 3 gene. Blood 90: 4062-4070.

Rousseau F, Bonaventure J, Legeai-Mallet L, Pelet A, et al. (1994). Mutations in the gene encoding fibroblast growth factor receptor-3 in achondroplasia. Nature 371: 252-254.

Schorderet DF and Gartler SM (1992). Analysis of CpG suppression in methylated and nonmethylated species. Proc. Natl. Acad. Sci. U. S. A. 89: 957-961.

Soong NW and Arnheim N (1996). Detection and quantification of mitochondrial DNA deletions. Methods Enzymol. 264: 421-431.

van Rhijn BW, van Tilborg AA, Lurkin I, Bonaventure J, et al. (2002). Novel fibroblast growth factor receptor 3 (FGFR3) mutations in bladder cancer previously identified in non-lethal skeletal disorders. Eur. J. Hum. Genet. 10: 819-824.

Zhu L, Somlo G, Zhou B, Shao J, et al. (2005). Fibroblast growth factor receptor 3 inhibition by short hairpin RNAs leads to apoptosis in multiple myeloma. Mol. Cancer Ther. 4: 787-798. 